\title{
Demonstration of Broadcast Transmission, and Wavelength Conversion Functionalities Using Photonic Crystal Fibers
}

\author{
Zsigri, Beata; Peucheret, Christophe; Nielsen, Martin Dybendal; Jeppesen, Palle
}

Published in:

I E E E Photonics Technology Letters

Link to article, DOI:

10.1109/LPT.2006.884736

Publication date:

2006

Document Version

Publisher's PDF, also known as Version of record

Link back to DTU Orbit

Citation (APA):

Zsigri, B., Peucheret, C., Nielsen, M. D., \& Jeppesen, P. (2006). Demonstration of Broadcast Transmission, and Wavelength Conversion Functionalities Using Photonic Crystal Fibers. I E E E Photonics Technology Letters, 18(21), 2290-2292. https://doi.org/10.1109/LPT.2006.884736

\section{General rights}

Copyright and moral rights for the publications made accessible in the public portal are retained by the authors and/or other copyright owners and it is a condition of accessing publications that users recognise and abide by the legal requirements associated with these rights.

- Users may download and print one copy of any publication from the public portal for the purpose of private study or research.

- You may not further distribute the material or use it for any profit-making activity or commercial gain

- You may freely distribute the URL identifying the publication in the public portal 


\title{
Demonstration of Broadcast, Transmission, and Wavelength Conversion Functionalities Using Photonic Crystal Fibers
}

\author{
Beáta Zsigri, Christophe Peucheret, Martin Dybendal Nielsen, and Palle Jeppesen, Member, IEEE
}

\begin{abstract}
Broadcasting functionality using cross-phase modulation in a nonlinear optical loop mirror utilizing 100-m highly nonlinear (HNL) photonic crystal fiber (PCF) as nonlinear element is demonstrated. This work presents entirely PCF-based network functionalities including broadcasting, transmission, and wavelength conversion. Broadcasting on four channels, transmission of one selected channel through one partially dispersion compensated 10.4-km PCF transmission link and wavelength conversion using four-wave mixing in a 50-m HNL-PCF at the ingress of the target subnetwork have been successfully demonstrated.
\end{abstract}

Index Terms-All-optical network, broadcasting, photonic crystal fiber (PCF), wavelength conversion.

\section{INTRODUCTION}

$\mathbf{M}$ ULTICASTING and broadcasting are essential functionalities in future all-optical networks [1]. For instance, specific information from a given source might have to reach several users located in a number of subnetworks. However, the different subnetworks might be operating on different wavelength sets, and therefore, wavelength conversion at the subnetwork ingress is a basic requirement. In future high-speed optical networks, the various signal processing functionalities will have to be realized in an all-optical way in order to overcome the electrical bottlenecks in the system.

Photonic crystal fibers (PCFs) are very attractive for optical communication since they open new possibilities for the design and fabrication of fibers with tailorable optical properties [2]. For instance, similar structures can be scaled to realize PCFs to be used for either transmission or signal processing purposes [3]. Transmission PCFs can be produced with pure silica core offering low loss [4], large effective area [5], and therefore, reduced fiber nonlinearity, as well as single-mode operation over a large bandwidth [6]. Highly nonlinear PCFs (HNL-PCFs) may offer large nonlinear coefficients and tailorable dispersion properties, and hence are attractive for all-optical signal processing [7].

In this letter, we demonstrate broadcasting, transmission, and wavelength conversion functionalities entirely based on PCFs. For the first time to our knowledge, broadcasting of four channels has been realized using cross-phase modulation (XPM) in a nonlinear optical loop mirror (NOLM) using PCF as the nonlinear element. Broadband wavelength conversion requires

Manuscript received May 1, 2006; revised August 2, 2006.

B. Zsigri, C. Peucheret, and P. Jeppesen are with COM•DTU, Department of Communications, Optics, and Materials, Technical University of Denmark, DK-2800 Kgs. Lyngby, Denmark (e-mail: bz@com.dtu.dk).

M. D. Nielsen is with Crystal Fibre A/S, DK-3460 Birkerød, Denmark.

Digital Object Identifier 10.1109/LPT.2006.884736

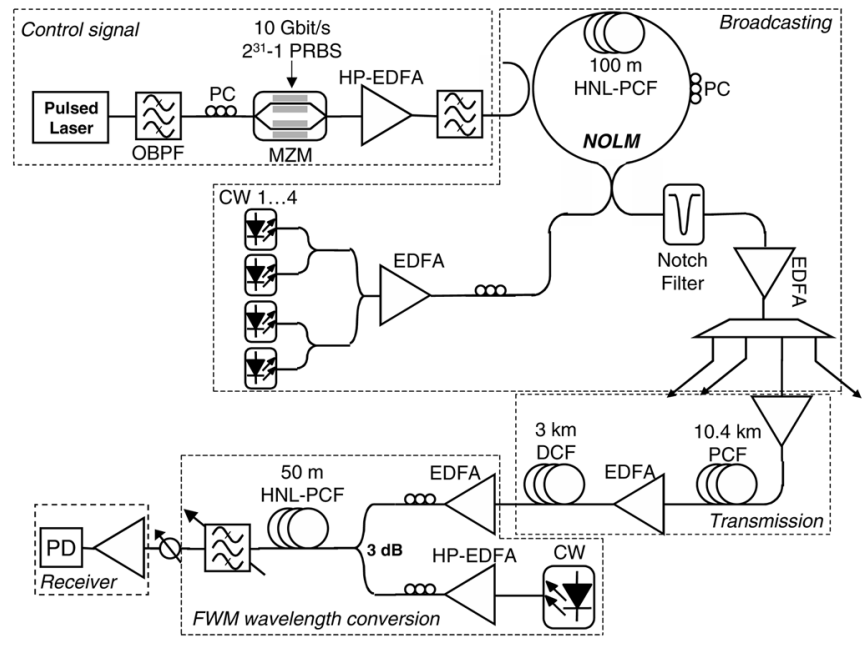

Fig. 1. Experimental setup.

a precise control of the dispersion properties of the HNL fiber, a feature offered by the HNL-PCF design used in this experiment [7]. Transmission to another subnetwork is achieved over 10.4-km transmission PCF, while wavelength conversion at the subnetwork interface is realized by four-wave mixing (FWM) in an HNL-PCF, thus demonstrating a prototype optical network entirely based on PCFs.

\section{EXPERIMENTAL SETUP}

The experimental setup is shown in Fig. 1. The broadcasting functionality was realized using XPM in an NOLM. The optical information signal at $1558.4 \mathrm{~nm}$ controlled the interference at the output of the NOLM (control signal). The information signal was generated by a pulsed laser (Erbium Glass Oscillator Pulse Generating Laser-2-ps pulsewidth) with $10-\mathrm{GHz}$ repetition rate. The pulse train was modulated by a $\mathrm{LiNbO}_{3}$ Mach-Zehnder modulator at $10 \mathrm{~Gb} / \mathrm{s}$ into return-to-zero modulation. The pseudorandom bit sequence length was $2^{31}-1$ bits. A high-power erbium-doped fiber amplifier (EDFA) amplified the control signal to an average output power of $25.2 \mathrm{dBm}$ before it was launched into the NOLM. Four continuous waves (CWs) at wavelengths of $1546.8,1548.25,1550.05$, and $1551.8 \mathrm{~nm}$ with an average power of $0 \mathrm{dBm}$ per channel were also input to the NOLM. In the NOLM, a 100-m-long highly nonlinear fiber (HNL-PCF) with a closely packed cladding structure and a triangular shaped hybrid core, resulting in an effective area of $8 \mu \mathrm{m}^{2}$ served as the nonlinear medium [7]. The nonlinear coefficient of the HNL-PCF was equal to $11 \mathrm{~W}^{-1} \cdot \mathrm{km}^{-1}$ and its dispersion was $\sim 3 \mathrm{ps} /(\mathrm{nm} \cdot \mathrm{km})$ at 
$1550 \mathrm{~nm}$ with variations less than $1 \mathrm{ps} /(\mathrm{nm} \cdot \mathrm{km})$ over $94 \mathrm{~nm}$. The loss of the 100-m HNL-PCF, including splices to standard single-mode fiber (SMF) pigtails was $3.3 \mathrm{~dB}$ at $1550 \mathrm{~nm}$. At the output of the NOLM, a notch filter eliminated part of the control signal before the four channels were amplified and demultiplexed by an arrayed waveguide grating (AWG) with passbands centered at 1546.92, 1548.51, 1550.12, and $1551.72 \mathrm{~nm}$ and with a 3-dB bandwidth of $0.72 \mathrm{~nm}$. This corresponds to the situation where the four multicasted channels would be routed to different subnetworks. One of the channels (at $1548.25 \mathrm{~nm}$ ) was further transmitted over a partially dispersion-compensated transmission span consisting of 10.4-km transmission PCF and $3 \mathrm{~km}$ of conventional dispersion-compensating fiber (DCF) and having a residual dispersion of $-53.9 \mathrm{ps} / \mathrm{nm}$ at $1548.25 \mathrm{~nm}$. The transmission PCF had a closely packed structure with a core formed by omitting one central air hole [8]. The spool was spliced from three fiber pieces. The fiber loss was less than $1 \mathrm{~dB} / \mathrm{km}$ at $1550 \mathrm{~nm}$ and its calculated effective area was $64 \mu \mathrm{m}^{2}$. Its dispersion was equal to $31.5 \mathrm{ps} /(\mathrm{nm} \cdot \mathrm{km})$ at $1550 \mathrm{~nm}$ with a dispersion slope of $0.067 \mathrm{ps} /\left(\mathrm{nm}^{2} \cdot \mathrm{km}\right)$. The nonlinear coefficient was measured to be $1.2 \mathrm{~W}^{-1} \cdot \mathrm{km}^{-1}$. After the transmission span, the signal was wavelength-converted (to match the wavelength allocation of the destination subnetwork) using FWM in a 50-m-long HNL-PCF with structure and nonlinear coefficient similar to those of the earlier described 100-m HNL-PCF. The loss of the 50-m HNL-PCF spool, including splices to SMF pigtails was $2.3 \mathrm{~dB}$ at $1550 \mathrm{~nm}$. The dispersion of this HNL-PCF was $-0.6 \mathrm{ps} /(\mathrm{nm} \cdot \mathrm{km})$ at $1550 \mathrm{~nm}$ with a dispersion slope of $0.012 \mathrm{ps} /\left(\mathrm{nm}^{2} \cdot \mathrm{km}\right)$. The signal was amplified and its state of polarization optimized for maximum conversion efficiency before it was input to the HNL-PCF together with a CW light pump with 27.2-dBm average power at $1544.4 \mathrm{~nm}$. At the output of the HNL-PCF, an optical bandpass filter filtered out the FWM product at $1540.34 \mathrm{~nm}$ before it was launched into a preamplified receiver consisting of an EDFA followed by a photodiode with $15-\mathrm{GHz}$ bandwidth.

\section{XPM-BASED NOLM WAVELENGTH CONVERTER}

The conversion bandwidth of the XPM-based NOLM wavelength converter was first investigated. For this specific measurement, the four CW lasers in Fig. 1 were replaced by an external cavity tunable laser source. The wavelength of the input signal was varied from $1536 \mathrm{~nm}$ up to $1556 \mathrm{~nm}$ with $2.5-\mathrm{nm}$ steps. The choice of the exact wavelength was determined by the transfer function of the NOLM. It was ensured that the XPM wavelength conversion was due to the interferometric operation of the NOLM by performing the selection of the converted signal by a tunable bandpass filter perfectly aligned with the converted signal. Eye diagrams of the original NOLM control signal (back-to-back) and the converted signals at wavelengths of 1536, 1546, and $1553.4 \mathrm{~nm}$ are shown in Fig. 2

The distortion due to wavelength conversion was quantified by measuring the power penalty of the converted signal compared to the original control signal to the NOLM at a bit-error rate $(\mathrm{BER})$ of $1.0 \times 10^{-9}$. The power penalty as a function of the wavelength detuning between the control signal and the converted signal is plotted in Fig. 3. Within the investigated $20-\mathrm{nm}$ band, the power penalties of the converted signals were between -0.3 and $1.5 \mathrm{~dB}$. Further increase of the detuning range was limited on the short wavelength side by the EDFA gain bandwidth
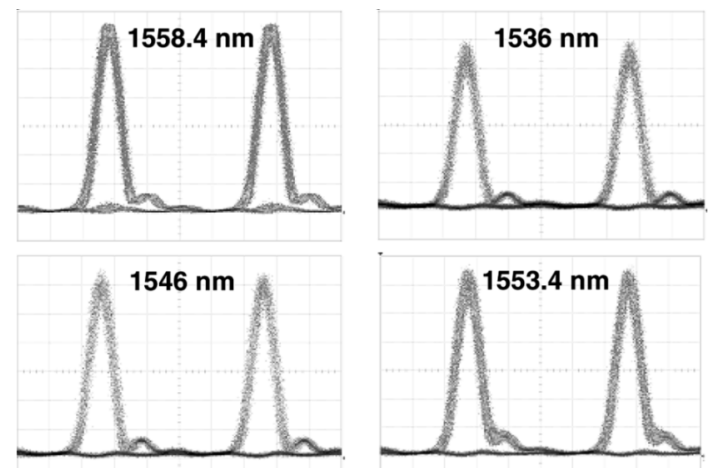

Fig. 2. Eye diagrams of the original NOLM control signal at $1558.4 \mathrm{~nm}$ and the wavelength converted signals at the output of the NOLM at wavelengths of 1536, 1546, and $1553.4 \mathrm{~nm}$. Horizontal scale: $20 \mathrm{ps} /$ div.

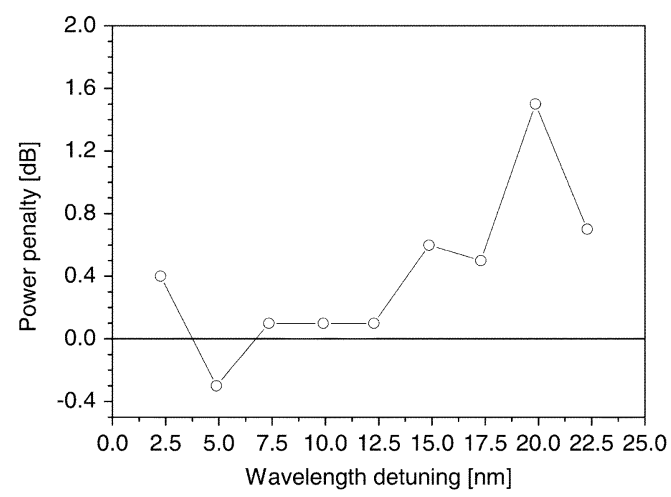

Fig. 3. Power penalty as a function of wavelength detuning between the control signal and the converted signal.

and on the long wavelength side by crosstalk from the control signal.

The obtained good performance over 20-nm bandwidth should permit the wavelength conversion to several wavelengths simultaneously, which in turn will allow the implementation of broadcast functionality.

\section{RESULTS}

Fig. 4 shows the spectra recorded at the NOLM output, at the FWM stage input, and at the FWM stage output. XPM-induced broadening of the four input $\mathrm{CW}$ channels is clearly visible on the spectrum recorded at the NOLM output. The spectrum also shows FWM products between the control signal and the four input channels. Due to the requirements on the input signal wavelengths set by the NOLM transfer function and the fixed wavelength allocation of the AWG used to filter out the broadcast channels, the filtering of the channel that was transmitted further is slightly asymmetric. This offset between the center wavelength of the filter and the transmitted channel resulted in slight performance degradation of the broadcasted channel.

In Fig. 5, the eye diagrams of the original control signal of the NOLM (a), the four broadcast channels recorded at the output of the AWG (b)-(e), after propagation through the transmission span including 10.4-km PCF and 3-km DCF and (f) and after wavelength conversion by FWM (g) are shown. The quality of the four broadcast channels is similar. After transmission, dispersion-induced pulse broadening is observable on the pulse. 


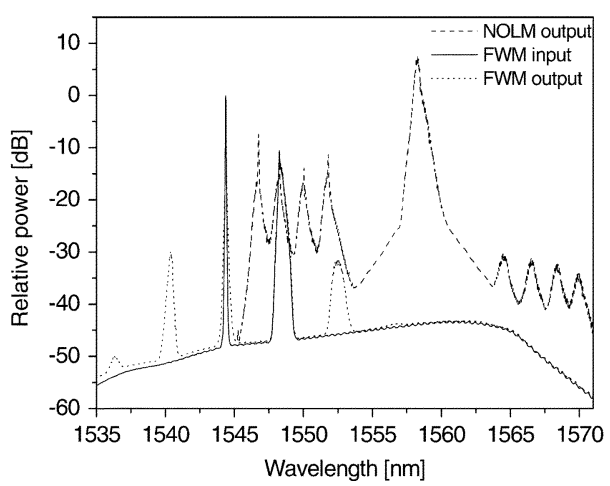

Fig. 4. Spectra recorded at the NOLM output (dashed line), FWM stage input (solid line), and output (dotted line) (resolution bandwidth: $0.01 \mathrm{~nm}$ ).
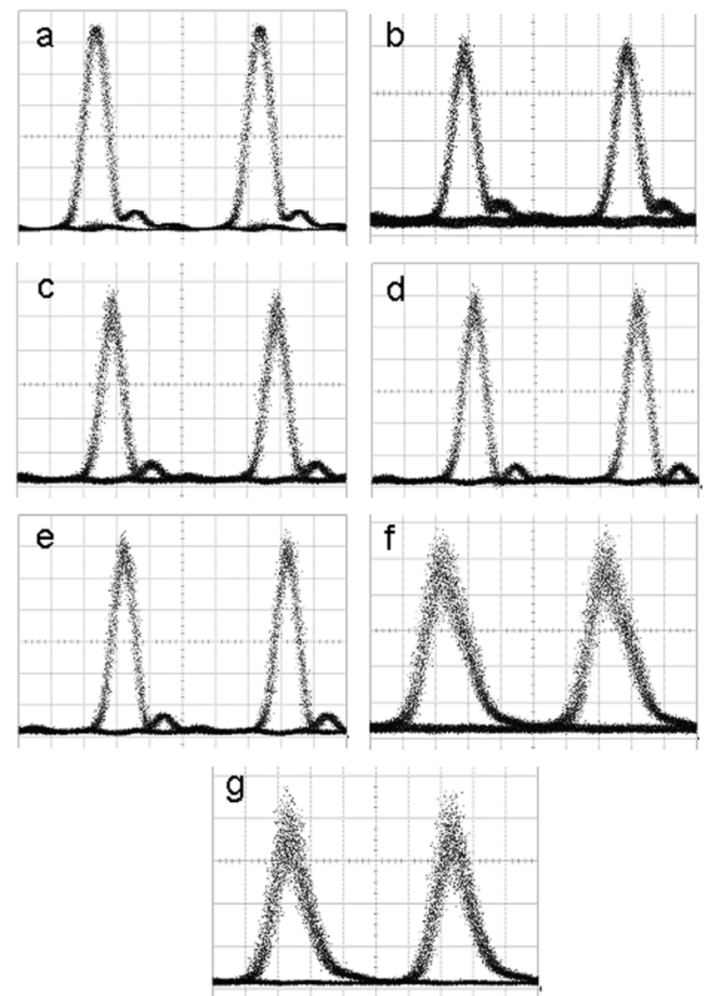

Fig. 5. Eye diagrams of (a) the original NOLM control signal, (b)-(e) wavelength converted signals at the output of the AWG, (f) channel at $1548.25 \mathrm{~nm}$ after transmission through 10.4-km PCF and 3-km DCF, and (g) at the output of the FWM wavelength conversion stage. Horizontal scale: $20 \mathrm{ps} /$ div.

The FWM wavelength converted pulse is noisy, even though the eye diagram is still wide open.

The BER curves of the corresponding cases have been measured and are plotted in Fig. 6 . The back-to-back sensitivity was $-29.2 \mathrm{dBm}$. The power penalties of the four broadcast channels were between 0.9 and $2.4 \mathrm{~dB}$. These penalties are higher than the ones measured when the NOLM has been used to wavelength convert to only one wavelength. The signal degradation compared to the single-channel wavelength conversion is attributed to FWM between the four input signals of the NOLM while they are propagating in the NOLM. The degradation caused by the

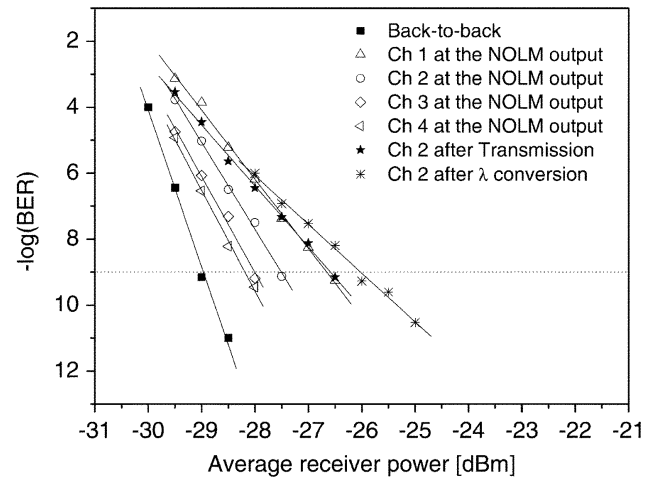

Fig. 6. BER as a function of average receiver power measured for the original NOLM control signal, the four converted signals at the NOLM output, the selected channel after transmission, and after FWM wavelength conversion.

transmission line is measured to be $0.9 \mathrm{~dB}$. The penalty induced by the FWM wavelength conversion is $0.6 \mathrm{~dB}$.

\section{CONCLUSION}

We have successfully demonstrated an optical network with functionalities including broadcasting, transmission, and wavelength conversion based entirely on PCFs. Broadcasting on four channels has been realized for the first time using XPM in an NOLM with 100-m highly nonlinear PCF as the nonlinear element. Transmission over $10.4-\mathrm{km}$ transmission PCF and wavelength conversion of a selected channel utilizing FWM in a 50-m-long HNL-PCF have also been successfully demonstrated.

\section{REFERENCES}

[1] K. K. Chow, C. Shu, C. Lin, and A. Bjarklev, "All-optical wavelength multicasting using four-wave mixing in a dispersion-flattened nonlinear photonic crystal fiber," in Tech. Dig. Conf. Lasers and Electro-Optics Eur. (CLEO Europe'05), Munich, Germany, Jun. 2005, p. 255.

[2] P. Russell, "Photonic crystal fibers," Science, vol. 299, no. 5605, pp. 358-362, Jan. 2003.

[3] C. Peucheret, B. Zsigri, P. A. Andersen, K. S. Berg, A. Tersigni, P. Jeppesen, K. P. Hansen, and M. D. Nielsen, "40 Gbit/s transmission over photonic crystal fibre using midspan spectral inversion in highly nonlinear photonic crystal fibre," Electron. Lett., vol. 39, no. 12, pp. 919-921, Jun. 2003.

[4] K. Tajima, J. Zhou, K. Kurokawa, and K. Nakajima, "Low water peak photonic crystal fibres," in Proc. Eur. Conf. Optical Communication (ECOC'03), Rimini, Italy, Sep. 2003, pp. 42-43, Postdeadline paper Th4.1.6.

[5] M. D. Nielsen, J. R. Folkenberg, and N. A. Mortensen, "Singlemode photonic crystal fibre with effective area of $600 \mu \mathrm{m}^{2}$ and low bending loss," Electron. Lett., vol. 39, no. 25, pp. 1802-1803, Dec. 2003.

[6] K. Nakajima, J. Zhou, K. Tajima, K. Kurokawa, C. Fukai, and I. Sankawa, "Ultra wide band $190 \mathrm{Gbit} / \mathrm{s}$ WDM transmission over a long length and low loss PCF," in Tech. Dig. Optical Fiber Communication Conf. (OFC'04), Los Angeles, CA, Feb. 2004, Postdeadline paper PDP23.

[7] K. P. Hansen, J. R. Folkenberg, C. Peucheret, and A. Bjarklev, "Fully dispersion controlled triangular-core nonlinear photonic crystal fiber," in Tech. Dig. Optical Fiber Communication Conf. (OFC'03), Atlanta, GA, Mar. 2003, pp. 806-808, Postdeadline paper PD02.

[8] B. Zsigri, C. Peucheret, M. D. Nielsen, and P. Jeppesen, "Transmission over $57.6 \mathrm{~km}$ of photonic crystal fiber," in Proc. Opto Electronics and Communications Conf. (OECC'04), Yokohama, Japan, Jul. 2004, pp. 482-483, Paper 14D1-2. 